\title{
Huge interatrial septal aneurysm with fenestrated atrial septal defect
}

\author{
Hakan Cakir, Muslum Sahin, Goksel Acar, \\ Elnur Alizade, Can Y. Karabay, Ahmet Guler
}

Department of Cardiology, Kosuyolu Heart and Research Hospital, Cardiology Clinic, Istanbul, Turkey

A 55 year-old man was admitted to our outpatients clinic with high blood pressure. Physical examination, electrocardiography and laboratory findings were normal except for a $2 / 6$ midsystolic murmur heard at the upper left sternal border. Transthoracic echocardiography showed a huge interatrial septal aneurysm extending to the right ventricular inflow (Fig. 1A). Atrial septal defect (ASD) was detected with color Doppler imaging
(Fig. 1B). The right heart chambers were of normal dimensions, and the calculated $\mathrm{Qp} / \mathrm{Qs}$ was 1.5. On transesophageal echocardiography, left to right shunt was found to be multiple (Figs. 1C-F). No patent foramen ovale was seen on contrast study. Surgical intervention was proposed for interatrial septal aneurysm with fenestrated ASD.

Conflict of interest: none declared
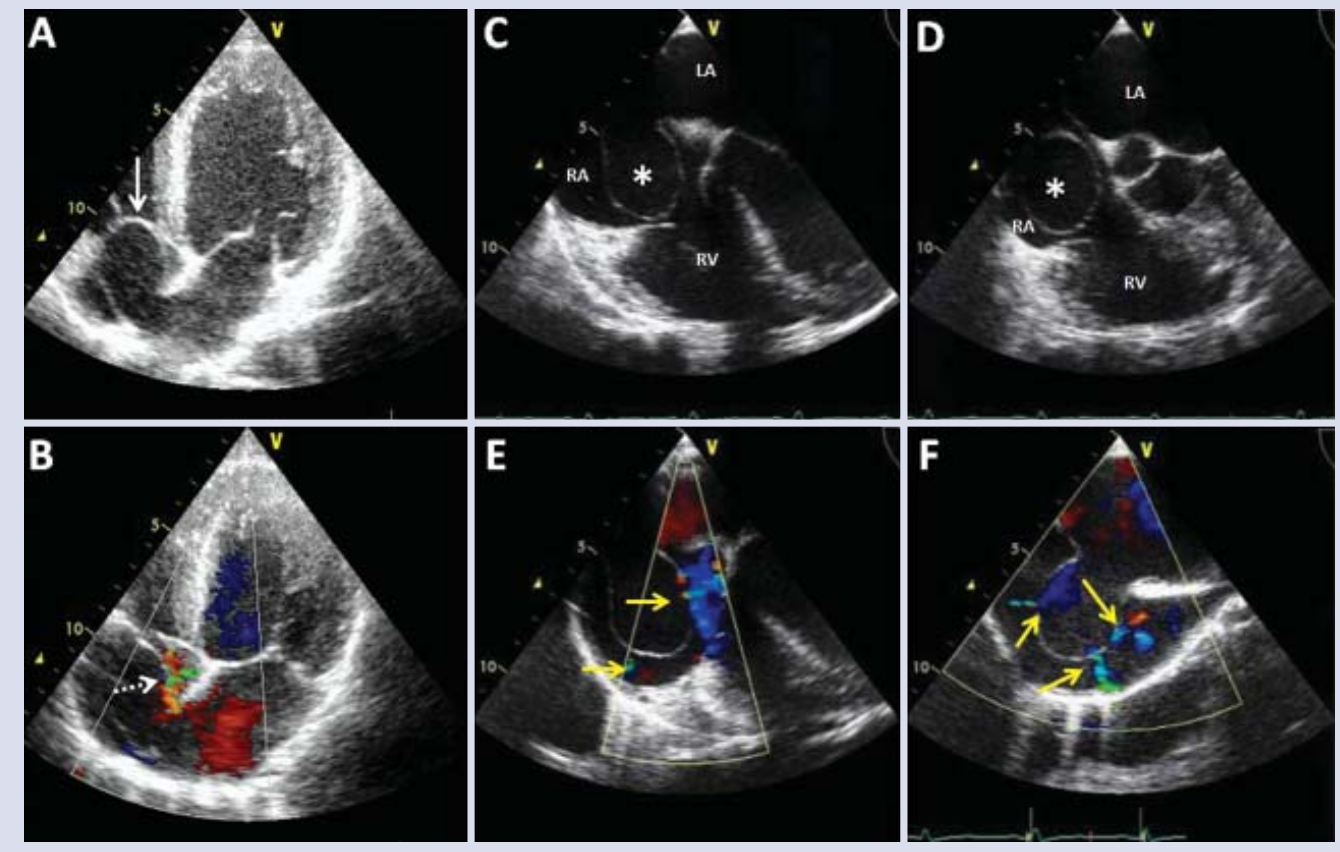

Figure 1. Transthoracic four-chamber view (A) showing interatrial septal aneurysm (arrow) extending to the right ventricular inflow and left-to-right shunt (dotted arrow) with color Doppler (B). Transesophageal four-chamber (C) and short-axis (D) views showing huge interatrial septal aneurysm (asterisks). Multiple atrial septal defects (yellow arrows) were seen with color Doppler on four-chamber (E) and bicaval views (F); RA — right atrium; LA — left atrium; RV — right ventricle.

Address for correspondence: Dr. Ahmet Guler, Kosuyolu Heart Education and Research Hospital, Department of Cardiology, Denizer Cad. Cevizli, Kartal, 34846 Istanbul, Turkey, e-mail: ahmetguler01@yahoo.com.tr

Received: 21.11.2011 Accepted: 01.12.2011 